\title{
Self-reflectivity: a moment of professionalization in psychotherapy training
}

\author{
Margarete Finger-Ossinger, ${ }^{1}$ Henriette Löffler-Stastka ${ }^{2}$ \\ ${ }^{1}$ Association for Person-Centred Learning, Psychosocial Education and Training; ${ }^{2}$ Clinic for Psychoanalysis and Psychotherapy, \\ Medical University of Vienna, Vienna, Austria
}

\begin{abstract}
The required basic skills of European psychotherapists were published by the European Association of Psychotherapy in 2013. One of these abilities is self-reflection. To mentalize oneself, to reflect on what circumstances and experiences in the past and present have led to the present desires, thoughts and convictions is an essential prerequisite for professional work in the psychosocial field. With the help of the thematic analysis a data set of 41 self-reflection reports of students is analysed at the end of the training. Since the training should be evaluated and if necessary optimized, it should be examined which elements of the online preparation course make the selfreflection ability visible. The analysis of the students' texts gives a clear indication of existing self-reflection skills. It was surprising that for some students, besides the great importance of self-awareness lessons, affective integration into the blended learning program was an essential impulse for self-reflection.
\end{abstract}

Key words: Psychotherapy; Blended-learning preparatory course; Self-reflectivity; Mentalization.

\section{Introduction}

Psychotherapy is a free health and healing profession. Psychotherapists work independently and on their own responsibility. They are responsible for all actions they take in the context of psychotherapy. The person of the psy-

Correspondence: Henriette Löffler-Stastka, Clinic for Psychoanalysis and Psychotherapy, Medical University of Vienna, Währinger Gürtel 18-20, 1090 Vienna, Austria.

Tel.: +43.0.1.40400.30700.

E-mail: henriette.loeffler-stastka@meduniwien.ac.at

Citation: Finger-Ossinger, M., \& Löffler-Stastka, H. (2018). Selfreflectivity: a moment of professionalization in psychotherapy training. Research in Psychotherapy: Psychopathology, Process and Outcome, 21(3), 137-148. doi: 10.4081/ripppo.2018.316

Contributions: MFO conducted the survey and wrote the manuscript; HLS conceived the design, read and commented serveral times the manuscript and supervised the whole process.

Conflict of interest: the authors declare no potential conflict of interest.

Funding: none.

Received for publication: 8 July 2018.

Revision received: 20 August 2018.

Accepted for publication: 27 August 2018.

This work is licensed under a Creative Commons Attribution NonCommercial 4.0 License (CC BY-NC 4.0).

CCopyright M. Finger-Ossinger and H. Löffler-Stastka, 2018

Licensee PAGEPress, Italy

Research in Psychotherapy:

Psychopathology, Process and Outcome 2018; 21:137-148

doi:10.4081/ripppo.2018.316 chotherapist, who is the main working tool, is an essential factor for the success of psychotherapy.

One of the basic competences required of the European Association of Psychotherapy (EAP, 2013) for the psychotherapist is the ability to reflect on oneself. Reflecting on one's own experiences and circumstances that have led to current desires, thoughts, belief systems is subsumed under the term mentalization, which is defined in this work as part of the ability of self-reflection.

In self-reflection I direct the light of my reason onto myself - in an attempt to analogize the physical process of reflection - and receive information about myself in reflection. I realize that there is me and the other people (objects, culture, world). The term self-reflection appeared only in the second half of the 20th century and is above all an expression of a desideratum in the human and social sciences. An essential step is to constantly reconcile this rearview mirroring from the outside world with one's own self-concept and to continuously evaluate and, if necessary, change it. The concept of the self is used differently in the sciences. From a psychological point of view, the concept of the self encompasses the feeling of unity, consistency, thinking and acting.

\section{Anthropological access to the self}

Immanuel Kant asks the questions in his lectures:

What can I know? What do you want me to do?

What can I hope? What is man? (Kant, Jäsche \& Kinkel, 1920, p. 27).

While the first question answers metaphysics, the second answers morality, the third answers religion, the fourth question answers anthropology, whereby Kant believes that 
the first three questions are ultimately summarized in the fourth question (Kant et al., 1920).

Anthropology, the science of man, makes man himself the object of investigation. While scientific anthropology, like evolution or genetics with scientific methods, investigates, analyses and explains causes, philosophical anthropology tries to understand phenomena in their entirety. Psychology and even more psychotherapy are hybrid forms that require both, scientific and humanistic methods for research and practical treatment (Hutterer, 1999, pp. 39-44 and pp. 117-125; Plessner, 1975; Scheler, 1949; Wundt, 1921). The different research approaches with their specific methods can be seen as the reason for the school dispute in psychotherapy.

\section{The human being - dependent on the other}

Results from attachment research show that people have self-reflection on the one hand and are dependent on this ability in others right from the start. Human life and experience always takes place in the social field, as a coexistence with others.

\section{Relationship between the ability to speak and (self-)reflection of the world we live in}

The world of life can be understood as the everyday world, which is pre-theoretical and pre-scientific. In the entire mentalist tradition from Descartes (1637/1961, p. 31, pp. 39-56) to Husserl (1913), reflection is primarily understood as self-reflection. Mentalism is the term used to describe philosophical approaches in the philosophy of mind and the theory of meaning. It is the basic position which means that consciousness and mental processes are states of a person, which assume causal roles and cannot be replaced by materialistic properties such as neurologically describable processes. By explaining behavior through externally inaccessible mental states, this direction differs from behaviorism (Stompe \& Schanda, 2010, pp. 3-14).

Language ability is the ability to communicate through language. This ability does not depend solely on physiological parameters, such as the speech centre in the brain, the vocal cords or the larynx, but is a specifically human, socially learned skill. Language is an activity aimed at cognition and communication. Frederick II's language experiments with children, who were only physically cared for and soon died despite the best physical care, show, that people are radically dependent on communication right from the start. Herder does not describe the origin of language in human sensations or as something divinely given, such as Süßmilch does (1766), but as an interaction between the development of reason and language (Herder, 1770/2013).

It is assumed that the ability to self-reflect and thus also the ability to mentalize oneself on the basis of one's own life story (Daudert, 2001, pp. 1-75) varies individually and can also be severely disabled (Fischer \& Riedesser, 1999, p. 344), but there is the possibility of improving it. Self-re- flection as a consequence of mind and thought process is always connected with language in the narrower sense. Something that cannot be named, such as feelings and body perceptions, cannot be reflected either. Stock and Riebenbauer (2014) demand that observation and description belong to the first stage of the self-reflection process. This approach is reflected in the concept of mentalization. We mentalize, when we become aware of what is going on in another person or what is going on in ourselves. Fonagy has put it in the succinct formula: Having Mind in Mind (Fonagy, Gergely, Jurist, \& Target 2005).

\section{Change in perspective}

An essential component of self-reflection is the change of perspective (Stock \& Riebenbauer, 2014). In systemic psychotherapy this change of perspective is promoted by specific questions.

Questioning one's own self-image is usually triggered when people reach their limits, whether in the family, in friends, at work or through illness, often accompanied by fear. Self-reflection needs a counterpart in which one's own self-concept, one's own self-image can be reflected upon; it is the encounter with other people that makes this possible. If self-awareness in education is to represent such a practice space, then this is not a series of techniques to be tried out, but rather this possible relationship space in which students can devote themselves to their own self-image without fear. Further training rooms for training candidates are in the context of the preparatory course the attendance seminars, the self-experience courses and the supervision.

\section{Materials and Methods}

\section{Technical information}

The theoretical part of the preparatory course consists of at least 760 hours on content from psychotherapy schools, psychology, social work, medicine, ethics and law. In Austria, it represents a binding part of the psychotherapy training before the start of the subject specific.

The practical part of the training consists of an internship of at least 480 hours in the psychosocial field, at least 50 hours of self-awareness or self-experience courses and 20 hours of supervision.

The Blended-learning preparatory course treated here has been training psychotherapy students in Austria since 2004. It combines distance learning phases with various interactive elements in the presence phases. In addition, students are required to write self-reflection reports on an ongoing basis.

\section{Five practice rooms of the Blended-learning preparatory course}

Theoretical online sequences: students are provided with 30-100 pages of scripts per theory unit as working ma- 
terial. The questions to be processed are randomly assigned by the technical system. Correspondence with the course supervisor takes place as an encounter in virtual space.

Classroom seminars: these take place five times as part of the training. They are offered in seminaristic form to deepen the theoretical contents and communicative networking of the participants.

Supervision and self-experience seminars: these must be completed with a psychotherapist registered in Austria with an additional qualification and at least five years of professional experience.

Internship: this includes work with persons who are suffering or have behavioural problems within the framework of an institution in the psychosocial or psychiatric field.

All students who completed the Blended-learning preparatory course between 1 June 2013 and 31 July 2015 were recorded. The data were collected on 15-29 September 2015 . Texts by 41 students ( 33 female, 8 male) were evaluated. The texts were read by four teachers. Only these four persons (the management team) and the webmaster have access to the platform (the data protection regulations have been observed!). The evaluation was carried out by a blinded rater. The study was not financed.

\section{Preliminary considerations}

One approach to describing a person's self-concept lies in narrative identity (Rammsayer \& Weber, 2010, p. 131). Mc Adams (Rammsayer \& Weber, 2010, p. 131) assumes that, from late adolescence, people strive to construct a more or less integrative narrative of themselves that gives their lives unity and meaning (Rammsayer \& Weber, 2010, p. 131) The self-evaluation texts can be seen as a specific form of narrative that varies from student to student. "The use of the life story as a date is possible above all when people are asked to tell their life story in a very specific form" (Rammsayer \& Weber, 2010, p. 131). The students' texts on the uniformly asked question present their personal learning history. The learning stories structured in this way and idiographically recorded can be evaluated according to content aspects and possibly be incorporated into a nomothetical research strategy (Rammsayer \& Weber, 2010, p. 131).

\section{Aim of the work}

This work is intended to contribute to optimising training in Blended-learning preparatory course, paying particular attention to the development of self-reflection. The individual practice rooms of the preparatory course e.g. online courses with support by coaches, attendance phases, supervision, self-awareness and internship are to serve as a grid.

\section{Hypothesis}

The hypothesis is that the qualitative evaluation of texts by means of differentiated categories according to Hierdeis $(2009 ; 2010)$ and Stock and Riebenbauer (2014, pp. 26-28) allows conclusions to be drawn about the students' ability to reflect on themselves at the end of their training in the preparatory course. Furthermore, it should become apparent in which areas of encounter (practice rooms) of the Blended-learning preparatory course the self-reflection ability already shows up, or in which areas improvements are necessary.

\section{Complementary considerations for hypothesising}

The self-evaluation to be given at the end of the preparatory course, at the earliest three weeks before the final examination, is based on at least three aspects. The questions, which the students should answer, demand the statement to the own personality development, the acquired theoretical knowledge and the practical experiences in the sense of a short guideline interview. Since the preparatory course in Austria was originally designed to bring different occupational groups who have access to training to the same level, personality development cannot be conclusively assessed.

The questions are open, so that the students are largely free to choose which aspects they want. Since the final evaluation is part of the immanent examination situation of the entire preparatory course, it must be assumed that at least some students would like to present themselves as positively as possible, but always report on areas that were and are relevant to them.

The hypothesis underlying this work is that the students in the seminar diaries represent their own learning in the sense of purely cognitive knowledge acquisition on the one hand, and as emotional events on the other. Thus, learning by experience in the broadest sense can be spoken of. In a next step, the self-reflection ability of the individual student is implicitly concluded as to how far the given conditions for this own learning are understood.

\section{Participants}

Since the present study contained texts by students that can be regarded as life stories (Rammsayer \& Weber, 2010, p. 131) and the students were not asked by questionnaire about their ability to reflect on themselves for ethical reasons, a possibility was sought to operationalize and evaluate their ability to reflect on themselves using the texts.

The texts were written on the basis of a central question, which must be answered in writing by all students shortly before the final examination, after completing at least 760 hours of theory, 480 hours of practical training, 20 hours of supervision and 50 hours of self-awareness.

\section{Ethical remarks}

The students are informed about the conditions of the Blended-learning preparatory course by the training contract. They also have precise information about the curriculum and the course of the training; in advance on the homepage of the Association and after registration on the 
training platform through a handbook. The final evaluation and all written texts are part of the training. They are informed that their learning evaluations have no influence on the further course of training.

By entering the Blended-learning preparatory course they agree to the conditions and of course they are free to take the preparatory course at another institute.

Already at the beginning of the Blended-learning preparatory course, the students are informed that only the management team, consisting of four persons, has access to their data and texts (on the multi-secured platform). The webmaster as technical supervisor of the platform is subject to the data protection regulation, which is contractually secured. The final reports are only ever read by the same four people. Also, only these four have knowledge of who completed the Blended-learning preparatory course during the relevant research period. In connection with this, their oral consent is obtained that their anonymised data may be used for research purposes (BMG, 2012).

The anonymization of the data was carried out in such a way that the initial letters of the first and last name were changed or swapped according to a system, so that no conclusions can be drawn about a certain person under any circumstances. This system is known only to the blinded rater.

\section{Collection of data}

All students of the Blended-learning preparatory course are requested to have written a final self-evaluation at the latest three days before the final examination. Students are assigned the following text on their learning platform:

Your written final evaluation must be available at least 3 days before the final meeting. Please assess your personal learning gain, which you have acquired by completing the preparatory course, in an overall view. At least take a stand on the following aspects: own personality development, acquired theoretical knowledge and practical experience. Minimum number: 4000 characters without spaces.

The texts are written by the students in the private or professional area at the PC or laptop. To what extent students define the final self-evaluation as a relevant part of the final examination is not known.

\section{Choice of method}

For ethical reasons, it is not appropriate to interview students via Reflective Functioning Questionnaire (Fonagy, 2016) at the end of the course. The qualitative evaluation of the self-evaluation texts using the differentiated categories according to Hierdeis (2009) and Stock and Riebenbauer (2014, p. 26-28), however, allows conclusions to be drawn about self-reflection.

These anonymous self-evaluation texts represent the data material.

In contrast to the usual method, for example according to McAdams (1993) of the semi-structured interview for life stories, the students were no longer asked about the texts, since these were no longer available after the completion of the preparatory course. This could tempt one to allow too much of one's own interpretation. In order to minimize these, the idiographically recorded life stories were first analyzed by means of thematic analysis according to Braun and Clarke (2006).

Qualitative research as a whole can be characterised by the fact that the data are asked questions that deal with people's thinking, perception and experiences. Qualitative research cannot test hypotheses, but describes phenomena and processes and interprets them (Willig, 2013, p. 8). The methods must be so open that they do justice to the complexity of the object under investigation. (Flick, 2004, p. 17). These requirements seem to be fulfilled by the thematic analysis.

\section{Thematic analysis by Braun and Clarke}

This method is a qualitative method already widely used in psychology. It provides flexible theoretical access to data analysis. It is a method for identifying, analyzing and pointing out topics that are contained in the data (Braun \& Clarke, 2006). It differs from other analytical methods that search for patterns in the data and are bound to theory, such as Grounded Theory (Barney, Glaser \& Strauss, 1967) or Interpretative Phenomenological Analysis (Smith, Flowers, \& Larkin, 2009).

The thematic analysis, as a qualitative research method, can be divided into different phases, which are flexible and do not require a linear process from phase to phase (Figure 1).

\section{Phase 1: Getting familiar with the data}

The texts were read several times. It was striking that the texts triggered different thoughts and emotions in the reader. It was striking that in some texts the causes of sensitivities were sought in the outside world, while in others the authors questioned themselves. This raised the question of the ability to self-reflect, as opposed to reflecting on external conditions. While the latter reflected on their own interpretations of the circumstances and experiences in the (near) past and present which had led further to present thoughts, wishes and convictions, the former persisted in demands or accusations against their environment by continuing a rigid pattern of interpretation.

Example: The father of my children is emotionally needy and very talkative. I have always tried to have a good relationship. During the therapy an extreme rage arose, because I didn't pay attention to my limits. He is no longer invited to dinner in the evening and the children are allowed to meet him alone in my apartment.

Example: In my professional work the border crossing is often done by teachers who burst into conversations and spread with private topics. Here I learned to ask to finish the topic in a polite, non-offensive or instructive way. 


\section{Phase 2: The generation of initial codes}

Every coherent thought of a writer was paraphrased. No part of the text was left out.

Example: I therefore experienced the practical parts of the preparatory course as very enriching, especially the meeting with the teachers and the other participants.

Paraphrase: Exchange with teachers and seminar participants was enriching.

\section{Phase 3: Search for motifs and categories}

After paraphrases had been created in phase 2, they were again combined into superordinate categories in phase 3 .

Example: Time management from the phase of independent time management was helpful, time flexibility was advantageous and challenging;

Paraphrase: own decision of work division was pleasant.

\section{Phase 4: Review of categories and definition of topics}

This phase starts after a set of categories has been formed. It must be ensured that there are enough data for these categories or that the data contained is too different, so that it does not actually represent a common topic. Some topics must be separated into separate topics after review.

Phase 4 contains two stages: Stage 1: the coded texts are read again to see if they show a coherent topic. If these topics do not fit, it must be decided whether the topic does not fit or whether some data do not fit into this topic. Then another topic can be found or another - already existing topic - can take up the data. Stage 2: is a similar process, but in relation to the whole data set. The meaning of the individual topics in relation to the data set is examined, but also whether the totality of the topics shows exactly the main statement of the entire data set.

Since the self-reflexiveness of students was to be examined, the categories were examined to what extent the statements were always referred back to the own person.

Phase 4 leds to the following main categories: i) Statements (on various topics); ii) Wishes and criticism (general); iii) Goals (general); iv) The own person before the training; v) Become a psychotherapist.

\section{Phase 5}

Being able to reflect on oneself, to reflect one's own experiences and circumstances that have led to current desires, thoughts, belief systems is subsumed under the term mentalization. It was assumed that this ability to reflect leads to a change in attitude or a practical action (self-reflection ability).

In phase 5 it was determined that in the evaluation of self-reflexivity only those passages of the text should be considered which explicitly cited a change of attitude or a practical action in order to make the mentalization competence visible.

\section{Phase 6}

This phase includes the presentation of the assumptions and the methodical approach in which the researcher becomes the active interpreter. All text passages are fully coded and the categories are checked against each other and in relation to the texts. Among other things, it also includes the presentation of the analysis path and the difficulties that arise (Braun \& Clarke, 2006).

In the individual main categories from phase 4 , those passages in the text that show a reflection were placed in a sub-category.

Since the interest in evaluating the data was to view and analyse it in terms of self-reflexivity, an operationalisation of self-reflection ability was sought. The following categories of Stock and Riebenbauer were used based on Hilzensauer (2008): i) Frustration tolerance; ii) Ability to endure criticism; iii) Recognizing and naming your own strengths and weaknesses; iv) Curiosity and interest.

On the one hand, the classification to the four categories was sought by explicit signal words in the students' texts. On the other hand, attention was paid to implicit text passages which justified the classification into the individual category in the sense of a qualitative evaluation.

The necessary preliminary stages of the possible process of changing the existing self-concept are the observation and description of the current state (first phase of a mentalization process) and above all the ability to ask open questions (Hilzensauer, 2008).

\section{Categories based on Hilzensauer}

Frustration tolerance: this is only possible if the questioning of one's own self-concept does not pose a threat to one's own self-consistency, which is in line with the findings of the Fonagy working group's attachment research (Fonagy et al., 2005).

Signal words: challenge, overcoming, difficult, strenuous.

Ability to bear criticism: This ability presupposes a certain experience of difference between what is and what should be.

Signal words: Misconception, admit that...

Recognizing and naming one's own strengths and weaknesses (the knowledge of one's own blind spots of perception)

Signal words: recognize, become aware, strength, error, weakness, frightening...

Curiosity and interest

Signal words: curiosity, curious, interest, interesting, motivated

Curiosity and interest show the ability to be ready to leave old attitudes and open up to the unknown.

These four categories, which, if they exist together, are defined as the basis for self-reflection, were examined again in a next step to see whether a change of attitude or a change of view of the students can be assumed and whether a concrete action has already been planned or set (Figure 1). 
Phase 1 and 2 - Becoming familiar with the data and generating initial codes.

\begin{tabular}{|c|c|c|c|c|c|c|c|c|c|}
\hline & Text & & Text & & Text & & & Text & \\
\hline Theme & Theme & Theme & Theme & Theme & Theme & Theme & Theme & Theme & Theme \\
\hline
\end{tabular}

Phase 3 - Search for motives and categories.

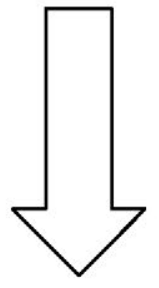

\begin{tabular}{|c|c|c|c|c|}
\hline Statements & Wishes, criticism & Aims & $\begin{array}{c}\text { Myself bevor the } \\
\text { training }\end{array}$ & $\begin{array}{c}\text { To become a } \\
\text { psychotherapist }\end{array}$ \\
\hline
\end{tabular}

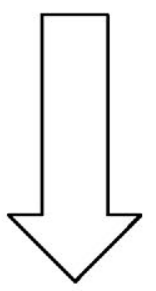

Phase 4 - Review of categories and definition of themes.

\begin{tabular}{|l|l|l|l|l|l|l|l}
\hline Reflection & Reflection & Reflection & Reflection & Reflection & Reflection & Reflection & Reflection \\
\hline
\end{tabular}

\section{SELF-REFLECTION}

\begin{tabular}{|c|c|c|c|}
\hline Interests & $\begin{array}{c}\text { Name one's own' } \\
\text { strengths and weaknesses }\end{array}$ & Frustration tolerance & Criticism ability \\
\hline
\end{tabular}

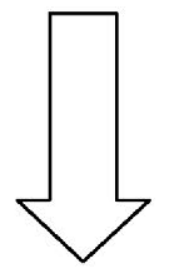

Phase 5 - Determination of the main categories.

\begin{tabular}{|l|c|c|c|}
\hline Attitude change & Attitude change & Attitude change & \\
\hline & & & Action leading \\
\hline
\end{tabular}

Phase 6 - Text passages are completely coded, categories checked against each other and in relation to the texts. The researcher becomes an active interpreter - of the assumptions and of the procedure.

\section{Self experience}

Practical training

\section{Online-course}

\section{Seminars}

Figure 1. Process of editing texts of 41 students after the thematic analysis of Braun and Clarke. 
Since the change of the internal attitude would also have to become action-guiding, which is relevant in practice, only those text passages were included in the final evaluation, which at least showed the concrete planning of actions. After Stock and Riebenbauer, preview and planning are the last step in good self-reflection. They require students to be able to describe exactly how they will proceed in the future and which modified actions can be implemented in future comparable situations (Stock \& Riebenbauer, 2014).

Example/self reflection competence available: In the course of the preparatory course I was able to deal with my own blind spots and recognize how important selfawareness is. I consciously chose to experience myself in two schools about which I did not yet know so much. Although I knew the theory of depth psychology, I did not know how it worked. I was surprised that the self-awareness in this school was not what I had expected. I also recognized some construction sites where I had to work on myself. (Recognizing and naming your own strengths and weaknesses).

What I learned for myself during my internship is that I don't want to work in the field of child psychiatry, although I would have an opportunity to work in this field. I could not do an internship in this field, although I would have been interested, but stories from other students already made me feel that I was not up to the task. Recognizing and naming my own strengths and weaknesses I myself have two children and think that I could keep too little distance from the life stories and experiences of the sick children.

In this example curiosity and interest are shown, own weaknesses were recognized, critical faculties and frustration tolerance are recognizable.

Example/few self-reflection skills available: Drawing the line to the father of my children: the father of my children is emotionally very needy and very talkative. I have always tried to have a good relationship with him. During the therapy an extreme rage arose because I didn't pay attention to my limits. He is no longer invited to dinner and the children are allowed to meet him alone in my apartment. I'll go away again.
This example shows neither curiosity nor interest.The circumstances and experiences of one's own life story (mentalization competence) are not named.

\section{Evaluation}

The evaluation of the text passages shows, that a large proportion of the text passages can be integrated into the categories according to Hierdeis (2009) which have been assumed for the operationalised ability of self-reflection (Table 1). However, only those passages of the text were explicitly used to answer the question in which a practical action was planned or set.

All passages in the text, which show a self-reflected, practical action were subsequently examined to what extent the practice rooms (Figure 2) of the preparatory course were mentioned as relevant and divided into these areas. Practical training, self-awareness lessons, supervision, online courses and face-to-face seminars were de-



Action

Figure 2. Reflection of the exercise areas causes action.

Table 1. Themes - main categories.

\begin{tabular}{llc}
\hline & & Number of coded phrases \\
\hline Themes: no reflection recognizable & & $\mathbf{4 9 1}$ \\
\hline & Wishes and criticism & 20 \\
& Statements & 378 \\
& Myself befor the training & 25 \\
& To become a psychotherapist & 64 \\
& Aims & 4 \\
\hline Main categories:reflection recognizable & & $\mathbf{1 8 9}$ \\
\hline & Frustration tolerance & 34 \\
& Criticism ability & 38 \\
& Name one's own strengths and weaknesses & 95 \\
\hline
\end{tabular}


fined as practice rooms. These are compulsory for all students. The private space was added as a further practice room, as it was frequently mentioned in the texts and should not be neglected.

These individual passages were also assigned to the 41 students, with reference to occupational groups and gender distribution (Table 2).

\section{Results}

\section{Self-reflection - guiding action}

It turned out that 23 out of 41 students are not shown explicitly with regard to the criterion action, 1 student 16 times, 2 students 4 times, 4 students 3 times, 4 students 2 times, 7 students 1 time (Table 2).

According to the male/female distribution, 17 out of 33 (almost $50 \%$ ) women and 6 out of 8 men (almost 75\%) have no text passage under explicit action. The multiple answers (3-4 times mentioned) can only be found among female students. The student 009 (Table 2) was not considered. Reading the text again, it became apparent, that this text had by far the largest volume, which probably led to a large number of coded text passages. All other parts of the text had roughly the same scope, which made them comparable (Table 3 ).

The occupations and trainings of the students in the cluster action are widely diversified. 4 people come from the field of education, 3 are psychologists, 2 work in nursing, 2 in social work, 2 lawyers, 1 doctor, 1 teacher, 1 economics trainer, 1 philosopher, 1 medical analyst, 1 kindergarten teacher. This distribution of occupational groups roughly corresponds to the professions of the enrolled students as a whole. It can be assumed, that the professional group has no influence on the ability to self-reflection, which is not necessarily assumed due to the small sample size.

\section{Meaning of the exercise areas}

The number of passages leading the text, assigned to the exercise areas, can be shown in the order self-experience (29 mentions), statements on all exercise areas undifferentiated (13 mentions), online courses (10 mentions), attendance seminars (6 mentions), supervision (5 mentions), private space (2 mentions).

\section{Self-awareness}

It is shown that the numerically largest proportion of the exercise areas mentioned by the students are in the area of self experience.

Example of self-experience:

But I have not only developed professionally in this time, also humanly. I started at the age of 24, meanwhile I am 28, the propaedeutic and here above all the self-awareness, has accompanied me in growing up. I
Table 2. Responses of students by number of citations (x) in the Action set section.

\begin{tabular}{|c|c|c|c|}
\hline \multicolumn{4}{|c|}{ Student's answers } \\
\hline \multicolumn{4}{|c|}{$\mathrm{X}=$ action leading } \\
\hline Name & Number of $x$ & Gender & Profession \\
\hline 001 & 1 & $\mathrm{~F}$ & Social worker \\
\hline 002 & 3 & $\mathrm{~F}$ & Pedagogue \\
\hline 003 & 0 & $\mathrm{~F}$ & Dance therapist \\
\hline 004 & 0 & M & Doctor \\
\hline 005 & 2 & $\mathrm{~F}$ & Teacher \\
\hline 006 & 0 & M & Theologian \\
\hline 007 & 0 & M & Theologian \\
\hline 008 & 0 & $\mathrm{~F}$ & Psychologist \\
\hline 009 & 16 & $\mathrm{~F}$ & Teacher \\
\hline 010 & 3 & $\mathrm{~F}$ & Education science \\
\hline 011 & 3 & F & Education science \\
\hline 012 & 4 & $\mathrm{~F}$ & Education science \\
\hline 013 & 1 & $\mathrm{~F}$ & Lawyer \\
\hline 014 & 3 & $\mathrm{~F}$ & Trainer/economic \\
\hline 015 & 4 & $\mathrm{~F}$ & Med. techn. analyst. \\
\hline 016 & 2 & $\mathrm{~F}$ & Lawyer \\
\hline 017 & 2 & $\mathrm{~F}$ & Social worker \\
\hline 018 & 0 & $\mathrm{~F}$ & Nurse \\
\hline 019 & 0 & $\mathrm{~F}$ & Education science \\
\hline 020 & 2 & $\mathrm{~F}$ & Psychologist \\
\hline 021 & 1 & $\mathrm{~F}$ & Nurse \\
\hline 022 & 0 & $\mathrm{~F}$ & Doctor \\
\hline 023 & 0 & M & Management consultant \\
\hline 024 & 0 & M & Psychologist \\
\hline 025 & 0 & M & Theologian \\
\hline 026 & 0 & $\mathrm{~F}$ & Coach \\
\hline 027 & 1 & M & Education science \\
\hline 028 & 0 & $\mathrm{~F}$ & Psychologist \\
\hline 029 & 0 & $\mathrm{~F}$ & Education science \\
\hline 030 & 0 & $\mathrm{~F}$ & Naturopath \\
\hline 031 & 1 & $\mathrm{~F}$ & Nurse \\
\hline 032 & 0 & $\mathrm{~F}$ & Teacher \\
\hline 033 & 0 & $\mathrm{~F}$ & Psychologist \\
\hline 034 & 0 & $\mathrm{~F}$ & Psychologist \\
\hline 035 & 0 & $\mathrm{~F}$ & Tourism \\
\hline 036 & 0 & $\mathrm{~F}$ & Psychiatrist \\
\hline 037 & 0 & $\mathrm{~F}$ & Education science \\
\hline 038 & 0 & $\mathrm{~F}$ & Biologist \\
\hline 039 & 0 & $\mathrm{~F}$ & Education science \\
\hline 040 & 1 & $\mathrm{~F}$ & Doctor \\
\hline
\end{tabular}


realize I don't need to rush through life. In this respect I would also like to take my time with the specific subject, after all it is also a matter of maturing personally in order to be able to carry out a responsible psychotherapeutic activity.

\section{Online courses}

It was surprising that the processing of the online courses and the technical challenges, especially in the area of curiosity and frustration tolerance, led the way.

Example: Experience with online courses:

It has struck me, that I always have to elaborate subject matter first and bring it into a form or shape that suits me in order to be able to classify and categorize everything and remember it in sequence.

I had to fight hard for self-discipline in parts and sometimes I didn't succeed either. In this aspect, too, the course was retrospectively instructive for personal development and work attitude.

\section{Attendance seminars}

The importance of the attendance seminars for the students was not so much in the acquisition of knowledge as in the practice of social skills.

Example: Experience in an attendance seminar:

I then took part in another integration seminar in April, this time "alone" without my colleague. I was a bit afraid of that, but I met the nice colleague from $X Y$ again and some other friends. I really liked this seminar better, and perhaps precisely because I was "alone", I could fit in better.

\section{Undifferentiated mentions}

The 13 undifferentiated mentions referred to the entire preparatory course:

Example: Statements on all practice rooms -undifferentiated:

The preparatory course has strengthened my desire to get an even more holistic view of mental health and illness. It has strengthened my desire to continue working in this direction, even if it is still a time-consuming and costly process.

Through the preparatory course I learned to think back to what is important to me and to take a different path in my life - to get out of the hamster cycle and more towards independence.

\section{Private space}

That the area of private experience is important for the students during the period of personal concentration on the propaedeutic and evokes changes can be seen in passages coded in this exercise room. This seems to deserve attention, since the students were asked in their text above all to describe their learning experiences through the propaedeutic.

Example: experience in the private sector:

Of course, the fact that I have become a mother has also contributed a lot to the maturation of my personality. I can't say exactly which part of it goes to which account. I look eagerly into the near future.

\section{Discussion}

\section{Notes on self-reflection ability}

Based on the results, it can be assumed, that just under half of the students of the Blended Learning preparatory course explicitly show self-reflection at the end. Just over half of the students who completed the preparatory course between 1 June 2013 and 31 July 2015, however, are not to be found in the action planned or set cluster. This is a finding that makes further investigations necessary as to the extent to which improvements in training are necessary.

A longitudinal study (development process of students during the training period) is planned. To strengthen the validity of a follow-up study, the application of the selfreflection and insight scale (Grant, Franklin, \& Langford, 2002) is considered before the start of the training.

Since the students should not only write a self-reflective text at the end of the training, but this is required after each of the five attendance seminars, the development of the self-reflection ability of an individual student can thus be reconstructed in a follow-up study on the basis of six texts.

Since self-reflection ability should be an essential competence of a psychotherapist, it should be promoted especially before the beginning of the subject specific.

An interpretation of the competence of the self-reflection ability according to gender or profession is not permissible due to the small sample, but could be interesting with regard to the exact evaluation of the text passages, which exist in the four categories of frustration tolerance, critical ability, strengths and weaknesses and curiosity, and is also considered for further work.

A larger study involving as many training institutions

Table 3. Text length per student essentially the same except 009.

\begin{tabular}{llllllllllll}
\hline 009 & 011 & 010 & 020 & 021 & 004 & 017 & 016 & 003 & 039 & 026 \\
& 015 & 023 & 014 & 025 & 019 & 022 & 028 & 001 & 007 & 041 \\
& 005 & 027 & 013 & 038 & 033 & 008 & 037 & 032 & 018 & 006 \\
\hline 002 & 012 & 035 & 040 & 024 & 031 & 034 & 030 & 036 & 029 & \\
\hline
\end{tabular}


as possible could provide indications as to which factors are conducive to self-reflection. Studies on the effect on practical work and the effect on clients with a lack of selfreflection could be connected.

\section{Notes on the practice rooms}

\section{Self-experience seminars}

With regard to the areas mentioned by the students which became particularly important to them during their training and which have also been coded with regard to self-reflection and action, it can be seen that the selfawareness plays an important role in the development of self-reflection. This is in line with the results of a study by Taubner (2016).

Since it is not clearly defined what self-awareness actually is or should be, it can be discussed how meaningful self-awareness seminars should look in order to promote self-reflection ability. If the promotion of mentalization in patients is demanded (Löffler-Stastka, Parth, Lodermeier, Gasl, \& Karwautz, 2014) and this leads to a better understanding of oneself and others, it can be discussed whether the concept of mentalization should be applied specifically in self-awareness seminars. The psychotherapist leading the seminar is then not an expert, but takes the attitude of the non-knowing person who actively asks. This questioning attitude can encourage students to understand themselves and others, which is also a sign of self-reflection. Results of attachment research show that, on the one hand, people have self-reflection and, on the other hand, are dependent on this ability in the other person from the beginning (Fonagy et al., 2005).

Peter Fonagy's research group was able to represent the missing link in bond research. Fonagy distinguishes two determinants that are the basis of a child's binding capacity. The first process refers to the attitude, the behaviour of the mother, the second process refers to the mother's ability to imagine the child as a spiritual-emotional, i.e. mental being. The child is therefore seen by the mother from the beginning with intentions, wishes and feelings. This requires the mother to reflect on the psychological state of the child and thus to go beyond mere attention and affection. However, this requires the ability for self-reflexivity. In the Reflective Self Functioning Scale (Fonagy, Target, Steele, \& Steele, 1998), the concept of mental processes and inner state of mind of the person interviewed is recorded and the extent to which he is able to abstract from his own experience when assessing the inner self, the intentions or the behavior of others, and to what extent persons are able to imagine their reference persons as mental beings. The construct of reflective-functioning is a concept described in the psychoanalytical, but also in the cognitive psychological literature. Mentalization and reflexivity are responsible for the development of a self that thinks and feels and are closely connected with self-representation. In contrast to pure introspection, they also contain the ability to produce sense and meaning and to regulate behaviour (Strauß \& Kohl, 2009, p. 417).

\section{Internship}

Another important area, which was mentioned by the students and coded in the cluster self-reflectivity-guiding action, is the internship. The evaluation shows that the concrete contact with suffering people contributes significantly to motivation and interest in the future profession. On the other hand, some reports also show that there may not be enough support from specialist staff to make massive demands on students. It seems that the internship makes a significant contribution to competence development and self-reflection. Strauß and Kohl (2009) note that there is still too little systematic evaluation of the practical parts (Strauß \& Kohl, 2009, pp. 411-426).

For the Blended-learning preparatory course it can be discussed whether the list of internship facilitiesof the Ministry of Health should be checked more often for its quality with regard to the instructions.

\section{Attendance seminars}

After reviewing the texts, the attendance seminars are essential for the students, above all for the exchange with colleagues from different professional fields and less through the theoretical input. Although they constitute an essential part of the training in all the preparatory courses offered in Austria and are favoured by the Ministry of Health, they are underrepresented in the cluster of self-reflection and leading action. Teachers are only implicitly mediators of knowledge. This is surprising in so far as the attendance phases in the curriculum of the blended learning preparatory course are obligatory to a lesser extent and especially the exchange with other students can be fruitful for personality development (in other preparatory course institutions the training is carried out to $100 \%$ by means of attendance seminars).

Since the ability to reflect on oneself is promoted above all through encounters with other people who also give benevolent feedback, the importance of attendance phases for training must be reconsidered.

Methodically it would be possible for the teacher to provide more guidance for personal exchange, since the theoretical input can take place in the online courses. A change of name to Dialogue Seminars would better identify the character of the seminars and also point to the importance of self-reflexivity. Finally, it can be said that half of the graduates have the ability to reflect on themselves at the end of the blended-learning preparatory course. Self-awareness is particularly important. This is in line with Strauß and Freyberger's (2009) wishes to expand their self-awareness and supervision.

Improvements in training must be considered in the area of face-to-face seminars, which represent the major part of the curriculum for almost all preparatory courses. 
In any case, frontal lectures are not very useful for the development of self-reflection without personal contact.

\section{Independent learning - Writing texts}

The evaluated texts on the online courses show that the challenge of dealing independently with the theoretical content as well as the technical conditions can promote the ability to delve deeper into the subject matter, the ability to structure and the motivation to do something. These passages were initially coded primarily in the areas of frustration tolerance and curiosity and seem essential for self-reflection.

The coaches were not consulted in any of the online course texts, although they evaluate, give feedback and complete the online courses. In this area, an improvement in blended learning preparatory course seems necessary. Originally the coaches were intended to interact with the students via the platform, which does not seem to have been successful. A survey of the coaches on their motivation is to be considered.

Since the seminar diaries can not only promote selfreflection but are also helpful for teachers in recording the development of the students, they are retained and especially read on the areas of frustration tolerance, strengths and mistakes, interest and critical ability.

\section{Conclusions}

Finally, it can be said that the self-reflection ability of the students is given at the end of the Blended - learning preparatory course with approximately half of the graduates.

In the field of exercises, self-awareness is particularly important, also from the student's point of view. This is in line with the wishes to expand self-awareness and supervision in the training of Strauß and Freyberger (2009, p. 410).

Since the concept of self-awareness or self-experience is very diffuse, it should be considered to define the necessary contents. For example, the concept of mentalization could be integrated into the design of selfawareness seminars.

The quality of the internship should be checked to see whether the students find professional guidance and are really in contact with sick people. It would be to pay attention to under- and overstraining of the students.

The attendance phases, which take up the largest part of the training in many training courses, should by no means only take place in frontal lectures. Increasing the number of phases to enable interaction among students and between students and professors would be conducive to the development of self-reflection.

The concept of blended learning is to check to what extent the interactive exchange and feedback of the learning supervisors is given. In principle, however, the required independent examination of technology, learning material and time management can promote self-reflexiveness.
Finally, a text by a student:

From my background I was strongly influenced by my studies. I was not accustomed to responding directly to my own emerging feelings in a written work. I always had a good feeling for what moved me and what was going on within me, but in the university environment I neither wanted to communicate this nor was one encouraged to reflect on myself. If you took a standpoint that you came up with through your own reflection, you had to justify it logically and on the basis of valid theories and not with what you felt. In my second degree in psychology I was mostly asked for pure factual knowledge - but I found this to be a great treasure during the exams in propaedeutics, which I could often fall back on. So it was a surprise for me (then) when I got my seminar diary back twice with the remark: "more self-reflection". Now I even have to smile about it when I'm writing. In this situation, I pretty much had to do the opposite of what I had been required to do for years. The self-reflection in the form of an own analysis of the emerging feelings and the written recording of it I had indeed first had to learn to this extent and see it now also as an important component of the way to be a psychotherapist.

\section{References}

Barney, G., Glaser, A. L., \& Strauss, C. (1967). The discovery of grounded theory. Strategies for Qualitative Research. Chicago, IL: Aldine.

Braun, V., \& Clarke, V. (2006). Using thematic analysis in psychology. Qualitative Research in Psychology, 3 (2), 77-101.

BMG - Bundesministerium für Gesundheit (2012): Berufskodex für Psychotherapeuten und Psychotherapeutinnen. Wien: BMG.

Daudert, E. (2001). Selbstreflexivität, Bindung und Psychopathologie. Zusammenhänge bei stationären Gruppenpsychotherapie-Patienten. Hamburg: Verlag Dr. Kovac.

Descartes, R. (1637/1961). Abhandlung über die Methode des richtigen Vernunftgebrauchs. Stuttgart: Reclam.

EAP - European Association of Psychotherapy (2013). The professional competencies of a european psychotherapist. Moscow: EAP AGM.

Fischer, G., \& Riedesser, P. (1999). Lehrbuch der Psychotraumatologie. München-Basel: Reinhardt.

Flick, U. (2004). Qualtiative Sozialforschung. Berlin: Rohwolt.

Fonagy, P. (2016). The Reflective Functioning Questionnaire (RFQ). Available from: https://www.ucl.ac.uk/psychoanalysis/research/reflective-functioning-questionnaire-rfq Access on 15.8.2018.

Fonagy, P., Gergely, G., Jurist, E., \& Target, M. (2005). Affect regulation, mentalization, and the development of self. New York: Routledege.

Fonagy, P., Target, M., Steele, H., \& Steele, M. (1998). Reflective-functioning manual. Version 5. For application to adult attachment interviews. Available from: https://www.mentalizacion.com.ar/images/notas/Reflective $\% 20$ Functioning $\% 2$ 0Manual.pdf Accessed: 20.8.2018.

Grant, A.M., Franklin, J., \& Langford, P. (2002). The self-re- 
flection and insight scale: a new measure of private self-consciousness. Social Behavior and Personality: an International Journal, 30(8), 821-836.

Herder, J.G. (1770/2013). Über den Ursprung der Sprache. Available from: http://gutenberg.spiegel.de/buch/abhandlung-uber-den-ursprung-der-sprache-2013/5 Accessed: 20.8.2018.

Hierdeis, H. (2009). Selbstreflexion als Element pädagogischer Professionalität. Vortrag am Institut für Erziehungswissenschaften der Universität Innsbruck am 26.10.2009. Available from: https://www.uibk.ac.at/iezw/texte/hierdeis.pdf Accessed: 20.8.2018.

Hierdeis, H. (2010). Selbstreflexive Lehrerbildung. In R. Göppel, A. Hirblinger, H. Hirblinger \& Würker A. (Eds.). Schule als Bildungsort und "emotionaler Raum". Der Beitrag der Psychoanalytischen Pädagogik zu Unterrichtsgestaltung und Schulkultur. Leverkusen, DE: Budrich. pp 175-197.

Hilzensauer, W. (2008). Theoretische Zugänge und Methoden der Reflexion des Lernens. Ein Diskussionsbeitrag. Bildungsforschung, 5(2).

Husserl, E. (1913). Ideen zu einer reinen Phänomenologie und phänomenologischen Philosophie. Erstes Buch: Allgemeine Einführung in die reine Phänomenologie. Halle: Niemeyer.

Hutterer, R. (1999). Das Paradigma der Humanistischen Psychologie. Entwicklung. Ideengeschichte und Produktivität. Wien: Springer.

Kant, I., Jäsche, G. B., \& Kinkel, W (1920). Immanuel Kants Logik. Ein Handbuch zu Vorlesungen. Leipzig: Haimann.

Löffler-Stastka H., Parth K., Lodermeier F., Grasl R., \& Karwautz A. (2014). Bindung und Beziehung - eine Analyse aktueller psychoanalytischer Forschungsansätze. Psychotherapie Forum 19, 68-74.

McAdams, D. (1993). Stories. We live by: personal myths and the making of the self. New York: William Morrow.

Plessner, H. (1975). Die Stufen des Organischen und der Men- sch. Einleitung in die philosophische Anthropologie. Berlin - New York: Walter de Gruyter.

Rammsayer, Th., \& Weber, H. (2010). Differentielle Psychologie - Persönlichkeitstheorien. Göttingen: Hogrefe.

Scheler, M. (1949). Die Stellung des Menschen im Kosmos. München: Nymphenburger Verlagshandlung.

Smith, J.A., Flowers, P., \& Larkin, M. (2009). Interpretative phenomenological analysis: theory method and research. London, UK: Sage.

Stock, M., \& Riebenbauer, E. (2014). Wegweiser durch die Theorie der (Selbst)Reflexion. Graz: Karl-Franzens-Universität - Institut für Wirtschaftspädagogik.

Stompe, Th., \& Schanda, H. (2010). Der freie Wille und die Schuldfähigkeit. In Recht, Psychiatrie und Neurowissenschaften. Berlin: Medizinisch Wissenschaftliche Verlagsgesellschaft.

Strauß, B., \& Freyberger, H. J. (2009). Ausbildungsforschung in der Psychotherapie. Ergebnisse des Forschungsgutachtens. Psychotherapeut 54, 409-410.

Strauß, B. \& Kohl, St. (2009). Themen der Ausbildungsforschung in der Psychotherapieforschung. Psychotherapeut 54, 411-426.

Süßmilch, J. P. (1766) Versuch eines Beweises, daß die erste Sprache ihren Ursprung nicht von Menschen, sondern allein vom Schöpfer erhalten habe. Berlin: Buchladen der Realschule.

Taubner, S. (2016). Das Mentalisierungskonzept. Available from: https://mentalisierung.net/das-mentalisierungskonzept/ Accessed 18.2.2016.

Willig, C. (2013). Introducing qualitative research in psychology. Berkshire: Open University Press.

Wundt, W. (1921). Logik. Eine Untersuchung der Prinzipien der Erkenntnis und der Methoden Wissenschaftlicher Forschung. Stuttgart: Enke. 